\title{
As memórias do PIBID na construção das subjetividades docentes: apontamentos sobre as práticas da história pública ensinada.
}

\author{
Leonara Lacerda Delfino ${ }^{1}$
}

Resumo: O artigo tem por objetivo analisar a construção das subjetividades docentes, atravessadas pelas práticas e abordagens emancipatórias desenvolvidas pelas ações coletivas entre os sujeitos escolares e equipes pibidianas do curso de história da Universidade Federal de Alfenas (UNIFAL) nas escolas públicas daquela cidade, entre 2014-2017. Os projetos selecionados reportam-se àqueles dedicados aos passados vivos, sobretudo aos temas das culturas africanas, afro-brasileiras e indígenas, em referência às Leis $\mathrm{n}^{\circ} 10.639 / 2003$ e $\mathrm{n}^{\circ} 11.645 / 2008$, cujas alterações curriculares reformularam a Lei de Diretrizes e Bases Nacionais (LBDN). Nosso estudo toma como base a História Pública Ensinada e a pedagogia decolonial para pensar temas subalternizados nos currículos prescrito e praticado, tais como a História da África e o protagonismo histórico dos sujeitos não brancos, enquanto elementos de descentramento para a construção da consciência histórica e subjetividades dos docentes em formação. Para tanto, utilizamos da metodologia da história oral, além da análise qualitativa de relatórios, avaliações de diagnósticos e projetos de intervenção do PIBID.

Palavras-chave: Pedagogia Decolonial. História Pública. Educação Étnico-racial. Leis 10.139/2003 e 11.645/2008. PIBID.

\section{The memories of PIBID in the construction of teaching subjectivities: notes on the practices of public history taught.}

\begin{abstract}
The article aims to analyze the construction of teaching subjectivities, crossed by emancipatory practices and approaches developed by collective actions between school subjects and Pibidian teams of the history course at the Federal University of Alfenas (UNIFAL) in public schools in that city, between 2014- 2017. The selected projects refer to those dedicated to living pasts, especially the themes of African, AfroBrazilian and indigenous cultures, in reference to Laws 10.639/2003 and 11.645/2008, whose curricular changes reformulated the Law of National Guidelines and Bases (LBDN). Our study is based on Taught Public History and decolonial pedagogy to think about subaltern themes in the prescribed and practiced curricula, such as the History of Africa and the historical protagonism of non-white subjects, as elements of decentering for the construction of historical consciousness and subjectivities of teachers in training. For this, we use the methodology of oral history, in addition to the qualitative analysis of reports, assessments of diagnoses and intervention projects by PIBID.
\end{abstract}

\footnotetext{
${ }^{1}$ Doutora em História. Pós-doutoranda em História (PPGH-Unimontes). Montes Claros-MG, Brasil. Email: leonaralacerda@yahoo.com.br. Orcid: https://orcid.org/0000-0001-5422-4980.
} 
Keywords: Decolonial Pedagogy. Public History. Ethnic-racial education. Laws 10,139/2003 and 11,645/2008. PIBID.

\title{
Las memorias del PIBID en la construcción de subjetividades docentes: apuntes sobre las prácticas de historia pública enseñadas
}

\begin{abstract}
Resumen: El artículo tiene como objetivo analizar la construcción de subjetividades docentes, atravesadas por prácticas y enfoques emancipatorios desarrollados por acciones colectivas entre sujetos escolares y equipos pibidianos del curso de historia de la Universidad Federal de Alfenas (UNIFAL) en las escuelas públicas de esa ciudad, entre 2014- 2017. Los proyectos seleccionados se refieren a aquellos dedicados a pasados vivos, especialmente los temas de las culturas africana, afrobrasileña e indígena, en referencia a las Leyes 10.639 / 2003 y 11.645 / 2008, cuyos cambios curriculares reformularon la Ley de Bases y Lineamientos Nacionales (LBDN) . Nuestro estudio se basa en la Historia Pública Enseñada y la pedagogía descolonial para pensar temas subalternos en los currículos prescritos y practicados, como la Historia de África y el protagonismo histórico de los sujetos no blancos, como elementos de descentramiento para la construcción de la conciencia histórica y subjetividades de los docentes en formación. Para ello, utilizamos la metodología de historia oral, además del análisis cualitativo de informes, valoraciones de diagnósticos y proyectos de intervención por PIBID.
\end{abstract}

Palabras clave: Pedagogía descolonial. Historia pública. Educación étnico-racial. Leyes 10.139 / 2003 y 11.645 / 2008. PIBID.

\section{Introdução}

Ao pesquisar, inicialmente, os saberes docentes construídos e mobilizados pelas práticas de ensino da história escolar, através das possibilidades de descentramento epistêmico incitadas pelas Leis $n^{\mathrm{o}} 10.639 / 2003^{2}$ e $11.645 / 2008,{ }^{3}$ percebemos - ao longo das entrevistas orais, da observação participante nos encontros semanais do Programa

\footnotetext{
${ }^{2}$ A reforma curricular de 2003 promoveu a alteração da "Lei no 9.394, de 20 de dezembro de 1996, que estabelece as diretrizes e bases da educação nacional, para incluir no currículo oficial da Rede de Ensino a obrigatoriedade da temática "História e Cultura Afro-Brasileira". De acordo com o Decreto, "nos estabelecimentos de ensino fundamental e médio, oficiais e particulares, torna-se obrigatório o ensino sobre História e Cultura Afro-Brasileira. § 1o O conteúdo programático a que se refere o caput deste artigo incluirá o estudo da História da África e dos Africanos.” Brasília, 9 de janeiro de 2003; Disponível em: http://www.planalto.gov.br/ccivil_03/leis/2003/L10.639.htm

Capturado em 24/05/2021.

${ }^{3}$ A reforma de 2008, em completo à Lei de 2003, prevê que: “ O conteúdo programático a que se refere este artigo incluirá diversos aspectos da história e da cultura que caracterizam a formação da população brasileira, a partir desses dois grupos étnicos, tais como o estudo da história da África e dos africanos, a luta dos negros e dos povos indígenas no Brasil, (...)" Disponível em: http://www.planalto.gov.br/ccivil_03/_ato2007-2010/2008/lei/111645.htm. Capturado em 24/05/2021.
} 
de Iniciação à Docência ${ }^{4}$, juntamente com o estudo qualitativos do material produzido pelo Pibid ${ }^{5}$ - que os sujeitos em processo de formação docente, se viram afetados, no campo subjetivo, pelas práticas emancipatórias desenvolvidas através das ações pibidianas nas escolas públicas de Alfenas. As entrevistas, ${ }^{6}$ ocorreram de modo remoto, em razão do isolamento social decorrente da pandemia da COVID-19 que se alastrou pelo mundo durante o primeiro semestre de 2020. De acordo com Santhiago e Magalhães (2021), a História Oral realizada em ambiente digital constrói outro tipo de interação subjetiva, uma vez que as plataformas de comunicação digitais podem re-criar sensibilidades, ao mesmo tempo em que a ausência do contato físico, face a face, pode comprometer a leitura de aspectos, tão apreciados pela metodologia da História Oral, tais como: gestualidade, corporeidade, direcionamento do olhar, entonação de voz, silenciamentos e outros comportamentos elementares no processo de decodificação da entrevista oral presencial.

Não obstante, levando em consideração os limites colocados pela interação remota, devemos mencionar que todas as pessoas entrevistadas já tiveram contato contínuo com a pesquisadora em momentos anteriores ${ }^{7}$ ao processo de isolamento social, o que facilitou a construção de uma desenvoltura mais espontânea e fluída durante o processo de interlocução e da produção de memórias e narrativas de $s i^{8}$ por esses sujeitos. As entrevistas foram realizadas pela Plataforma Digital via Skype, entre 12 de março a 25 de junho de 2020. Os sujeitos colaboradores possuem entre 20 a 42 anos. Dos 16 ex-pibidianos, nove são mulheres e sete dos entrevistados pertencentes ao

\footnotetext{
${ }^{4}$ Durante o ano de 2017 freqüentei as reuniões semanais conduzidas pelos professores coordenadores do Pibid de história na Universidade Federal de Alfenas. Neste período, elaborei um diário de campo, com intuito de anotar os comportamentos grupais desenvolvidos pelos alunos, na época, participantes do PIBID.

5 Foram consultados os projetos das sequências didáticas, além dos relatos de experiências, atas de reuniões e as avaliações de diagnósticos das intervenções referentes aos anos de 2014 a 2017.

6 Ao todo foram 25 sujeitos entrevistados. Destes, 16 ex pibidianos ( 9 mulheres e 7 homens); Três professoras regentes escolares; seis professores da Unifal (três mulheres e três homens). Para este artigo, utilizamos apenas das narrativas dos (as) egressos do Pibid.

${ }^{7}$ Dos 16 ex-pibidianos entrevistados, 12 foram meus alunos durante o tempo em que fui professora substituta na cadeira de Laboratório do Ensino de História e Estágio Supervisionado, entre 2015 e 2016 no curso de História da Universidade Federal de Alfenas.

8 A narrativa que o indivíduo constrói sobre si é a possibilidade de reconstrução de um sujeito historicamente situado, a partir das relações e jogos de poder / saber que a sociedade e o tempo, onde este produz a narrativa lhe permite se movimentar. Devemos considerar a relação intersubjetiva nesta provocação do outro para que o sujeito reconstitua sua experiência a partir das memórias produzidas nas relações de poder do presente. A narrativa de si dos (as) ex-pibidianos (as) nos faz adentrar em territórios existenciais, em representações, em significados construídos sobre a docência e sobre as aprendizagens elaboradas a partir da experiência no Programa de Iniciação à Docência. Para saber mais sobre nas "narrativas de si", ver: FOUCALT, 2009.
} 
sexo masculino. A maioria já exerce a profissão de regente escolar em instituições públicas do Ensino Básico. ${ }^{9} \mathrm{~A}$ princípio, elaboramos um roteiro semi-aberto, (semiestruturado) de modo com que as perguntas fossem re-elaboradas conforme o direcionamento das falas produzidas pelos (as) colaboradores (as), ao relatarem suas memórias pibidianas em interface às suas experiências profissionais docentes e acadêmicas. As identidades subjetivas e sociais são aqui compreendidas como um processo contínuo, dinâmico, múltiplo e ininterrupto, portanto, sempre inacabado e múltifacetado. Bauman (2005), ao tratar sobre as identidades, problematiza a liquidez do mundo pós-moderno e a dificuldade de assentar raízes sólidas nos modos de identificação desses sujeitos. Nesta perspectiva, os sujeitos buscam sentidos para suas experiências, nem sempre coesas, coerentes ou monolíticas. Levando em consideração este aspecto camaleônico, o processo de subjetivação docente também é atravessado por múltiplas experiências fragmentadas e por efeitos de verdade produzidos pelos discursos sociais que interseccionam as práticas e a fabricação desses mesmos sujeitos.

Dito isso, reunimos elementos comuns dessas narrativas de si, tomando por base a experiência pibidiana.

A experiência pibidiana foi fundamental para a definição da escolha da carrreira docente, no sentido concreto da palavra. A maioria relatou, em entrevista, que entrou no curso de história sem o interesse imediato de trabalhar no campo do magistério. Argumentos como, desvalorização da carreira docente, falta de investimentos e de políticas públicas de incentivo e promoção da permanência do profissional da educação na área foram mencionados como motivos desse desinteresse inicial. Outro ponto abordado foi a superação de estereótipos cristalizados pelo imaginário social hegemônico, percepções que rotulam o (a) professor (a) como "sofredor permanente"; "sacerdote/missionário"; ou aquele que trabalha exclusivamente por amor ou outras percepções ingênuas do ofício. Além disso, a experiência pibidiana permitiu uma relação mais humanizada com o espaço escolar, para além das críticas superficiais, como falta de estrutura física, indisciplina, aprovação compulsória, etc. Mais efetivamente do que o estágio supervisionado, a interação continuada viabilizada pelas

\footnotetext{
${ }^{9}$ Das nove entrevistadas: cinco eram professoras regentes, duas interromperam o curso e atuam em outros ofícios (aromaterapia e recepcionista) e duas são mestrandas-bolsistas de programas de pós graduação em história. Entre os sete rapazes, seis são professores regentes e um, matriculado no sétimo período do curso de Licenciatura em História. Do total de entrevistados, tivemos uma professora que atuava também como supervisora pedagógica e secretária da educação em seu município; e um professor que trabalhava na gestão escolar como supervisor.
} 
intervenções didáticas do Pibid permitiu o aprofundamento do aprendizado, a partir de temas selecionados que eram desenvolvidos através de sequências didáticas. A convivência diária com os educadores regentes e a interações sociais com os sujeitos aprendentes (MONTEIRO, 2007) possibilitou uma construção de estratégias e táticas cotidianas (CERTEAU, 2005) ensinando esses profissionais em formação os modos possíveis de como lidar com as adversidades e dificultadas colocadas pela estrutura escolar; por outro lado, a inserção corpórea e afetiva dos pibidianos (as) nas relações intersubjetivas da cultura escolar (FRAGO, 2008) transformou as percepções préconcebidas sobre o que é ser educador, o que é trabalhar com a crianças e adolescentes, tendo em vista, a diversidade de auto-compreensão desses alunos e alunas e seus modos de aprender história e de construírem aprendizados significativos, redefinindo seus sentidos de existências e de leituras de mundo.

O trabalho com os "passados sensíveis" (ABREU, MATTOS, GRINBERG, 2019; GRINBERG, 2019) e a construção de uma pedagogia decolonial ${ }^{10}$ em sala de aula foi um tema mencionado durante as entrevistas orais e identificado pela leitura do material empírico produzido pelo Pibid (relatórios, projetos de intervenção, avaliações de diagnósticos), denominado aqui por "diários de campo. A escolha dos temas era feita a partir de um questionário (avaliação de diagnóstico), primeiro passo para se pensar a confecção coletiva das intervenções didáticas. Feito este levantamento, os (as) pibidianos levavam para a coordenação do Pibid na Universidade quais eram as demandas escolares e os temas de interesse anunciados pelo público escolar. Com esta coleta era possível perceber que os temas elencados eram temas que diziam respeito aos

${ }^{10}$ Definida como campo do saber contra-hegemônico, a pedagogia decolonial (WALSH, 2014) tem por objetivo descolonizar práticas, pensamentos e atitudes na cultura escolar e na estruturação das políticas públicas curriculares, ao tecer críticas ao eurocentrismo e redimensionar grupos invisibilizados pelas narrativas universalizantes. Nesse sentido, a noção de colonialidade do poder prescreve os processos de re-invenções de subalternização dos povos colonizados em contextos vigentes na contemporaneidade. Dito de outra maneira, a descolonização histórico-política não significou, necessariamente, o fim do colonialismo enquanto relação social de reprodução de desigualdades materiais, simbólicas, identitárias no tempo presente. A colonialidade se reproduz e se recria continuamente sob novas formas de poder, fazendo dos centros hegemônicos os espaços de enunciação privilegiados no campo do conhecimento, sem que tal processo seja colocado na narrativa destes saberes ocidentais. Nesta perspectiva, a crítica decolonial desestabiliza o paradigma iluminista do conhecimento, ao confrontar-se diretamente com o ideal de neutralidade pretendido pela universalidade eurocêntrica excludente. Devo mencionar aqui a contribuição das diversas vertentes para a desnaturalização do universalismo epistemológico ocidental. Dentre elas, várias frentes da crítica feminista (ver: BALLESTRIN, 2007), junto aos estudos subalternos desenvolvidos na Índia (ver: SPIVAK, 2010), o orientalismo de Said (1974), a produção de intelectuais africanos, como Franz Fannon (1968) e Almir Cézaire (1978), e o grupo de estudos latino-americano Modernidad/colonialidad, composto por intelectuais como Henrique Dussel (2005), Walter Mignolo (2008) ,Anibal Quijano (2005), Arturo Escobar (2005), dentre outros/as. 
afetos subjetivos desses alunos e suas experiências, ao mesmo tempo, eram temáticas que faziam referência às memórias traumáticas coletivas muito debatidas no espaço público, seja pelas mídias digitais (redes sociais, blogs, canais de Youtube), seja pelas mídias tradicionais (TV, Cinema, etc.). Outrossim, destes conteúdos selecionados, podemos destacar: a questão abolicionista e a luta por direitos sociais dos negros libertos; o genocídio indígena durante a expansão de fronteiras; as mulheres na Revolução Francesa; as representações do feminino nos periódicos na Era Vargas; a resistência do povo judeu durante os regimes totalitários; a história da África, através da literatura; as memórias da ditadura militar e os crimes contra os direitos humanos. Para atender os objetivos de análise deste artigo, selecionamos apenas os projetos referentes à história da África e à história dos povos negros e indígenas no Brasil. Não obstante, observamos que a preocupação dos pibidianos em dialogar com os múltiplos espaços do conhecimento, levando em conta os processos formais e não formais de aprendizado fez com que o uso das Tecnologias Digitais de Informação e Comunicação (TDICs) não se configurasse como uso ilustrativo ou externo à abordagem do letramento histórico construído coletivamente em sala de aula, mas como instrumentos ativos e integradores dos processos de construção de aprendizagem e de produção de sentidos de história ensinada.

O terceiro ponto a ser destacado são as memórias pibidianas e suas relações com a construção das identidades docentes e os processos de subjetivação que atravessam os modos de identificação e auto-representação desses sujeitos em suas práticas docentes ou de práticas de formação continuada. Segundo, Rovai (2013, p. 110), a memória narrada "reúne elementos dispersos, (...), por meio dos quais [os sujeitos] reconstituem sua própria unidade e identidade num tempo que a narrativa revela complexamente subjetivo, emotivo e racionalizado." Quando o sujeito se narra, ele reconstrói suas lembranças a partir das vivências, tensões, problematizações e intencionalidades do presente. Deste modo, os colaboradores relataram suas experiências pibidianas em interface às suas memórias escolares, vivências acadêmicas e experiências profissionais na educação. Nestas falas, emergiram histórias de vida, mesmo se tratando de entrevistas temáticas. ${ }^{11}$ As subjetividades, as relações de afetos e desafetos, os traumas

11 Segundo Verena Alberti (2011, p. 175), “as pesquisas temáticas são aquelas que versam prioritariamente sobre a participação do entrevistado no tema escolhido, enquanto as de história, incluindo sua trajetória desde a infância até o momento em que fala, passando pelos diversos acontecimentos e conjunturas que presenciou, vivenciou ou de que se inteirou." 
acadêmicos, as dificuldades de se entenderem como educadores na atual conjuntura política são questões que emergiram com força nos depoimentos dados. Outrossim, as vivências multirreferenciadas que atravessaram o Pibid ou as que se fizeram a partir das experiências coletivas no próprio programa foram fundamentais para a recontextualização dos sentidos dados ao exercício de ensinar e aos saberes docentes construídos diariamente pelo cotidiano escolar. Deste modo, as trajetórias pessoais, acadêmicas e profissionais foram re-significadas pelo atravessamento dessas experiências multirreferenciadas que, de certo modo, se entrecruzaram nas memórias pibidianas narradas pelos sujeitos já licenciados, muitos em exercício nas escolas como regentes. Com efeito, as memórias pibidianas revelaram experiências de confronto com uma escola idealizada; as relações interacionais com os sujeitos aprendentes, docentes e com o próprio público escolar, de modo mais amplo, contribuíram para a problematização de uma concepção elitista de espaço escolar, ainda vigente no senso comum. Um ponto convergente nas falas construídas foi de que o Pibid fez com que esses sujeitos percebessem a situação de realidade escolar "a partir de dentro" e não de fora. Eles passaram a se sentir pertencentes à comunidade escolar, não mais como "visitantes externos" aptos apenas a observar e criticar do ponto de vista externo e passivo. A pesquisa-ação mobilizada, de forma coletiva, através das intervenções didáticas, viabilizou a construção de um conhecimento colaborativo, em que alunos (as), professores e pibidianos elaboraram sentidos vivos para a história ensinada. Esse processo se deu por meio da valorização e diálogo com os conhecimentos prévios dos alunos e alunas que, ao re- significarem suas experiências, passaram a se ver como sujeitos históricos não mais deslocados em narrativas externas às suas experiências sociais. Deste modo, entendemos que a transformação dos afetos e suas relações com a construção da consciência histórica e re-significação das formas de percepção no mundo (processos de subjetivação) se estabeleceram como trocas dialógicas, pois, "quem ensina aprende ao ensinar e quem aprende ensina ao aprender (FREIRE, 1996, p. 25).

A seguir teceremos uma análise sobre as práticas emancipatórias desenvolvidas a partir da rede interacional escola-universidade. Apresentaremos os projetos selecionados para a análise, os resultados obtidos e a produção dos diários de campo, ou seja, o conjunto de relatos dos bolsistas acadêmicos sobre as impressões dos trabalhos desenvolvidos nas escolas. Relatos esses que abordam desde as impressões da estrutura física e dos modos de ocupação do espaço escolar; as leituras prévias de mundo dos 
alunos e alunas; as percepções construídas sobre os passados sensíveis, e os sentidos elaborados na interação com os alunos sobre as percepções se si e do mundo, isto é, os modos de produção da consciência histórica mediadas pela história escolar ensinada pensada a partir da rede colaborativa desses agentes. No segundo momento, a análise se concentrará, sobretudo, na produção de memórias pibidianas e suas relações com as subjetividades desses sujeitos docentes. Vamos tratar sobre a complexa produção dos saberes docentes (TARDIF, 2002) e suas relações com as formas de compreensão de si, mediadas pelo ato de ensinar, ou seja, de suas identidades docentes, entendidas como processos contínuos atravessados por experiências intra e extra-escolar.

\section{Os passados sensíveis e os relatos de experiências nos diários de campo}

Ao conjunto dos relatos de experiências presentes nos documentos institucionais do Pibid, tais como: as avaliações de diagnósticos, projetos de intervenção e os relatórios finais, atribuímos o nome de "diários de campo". A denominação se justifica em razão desses documentos disponibilizarem as experiências grupais, as sensibilidades, as dificuldades e outras percepções cotidianas construídas nas interações entre os professores em formação com os sujeitos escolares durante o tempo das intervenções. Feita a avaliação de diagnóstico (primeira etapa para a escolha do tema que nortearia os projetos de intervenções), as equipes pibidianas (formadas por dois, três ou mais acadêmicos) davam início a elaboração e desenvolvimento das seqüências didáticas. Os planos de intervenção não eram fechados ou estáticos, ao longo das aulas, as equipes desenvolviam uma relação de autocrítica com suas formas de aprender a ensinar e poderiam, conforme as percepções dialógicas com os/as alunos/as, modificar as estratégias de ensino-aprendizagem. Uma marca de destaque que se manteve constante durante as experiências pibidianas no espaço escolar foi o trabalho intensivo com outras linguagens como recursos didáticos, tais como: a literatura, a música, o cinema, os festejos regionais, o teatro, os HQ's e histórias em quadrinhos, além do uso de plataformas digitais e das mídias tradicionais (principalmente a televisão). O diálogo com as diferentes linguagens e o uso das mídias digitais como recursos didáticos abriram espaço para a compreensão da história na arena pública: os usos do passado, a construção das narrativas, os caminhos para ensinar os/as alunos/as a compreenderam os lugares de produção dos discursos, suas intencionalidades e historicidades. Com efeito, os sujeitos escolares puderam desenvolver o que Peter Lee (2006) chama de letramento histórico escolar, isto é, o raciocínio histórico capaz de desnaturalizar discursos 
equivocados sobre o passado, calcados no anticientificismo, revisionismo conservador e nos processos de invisibilização das minorias e perpetuação de preconceitos, como o machismo, a homofobia, o racismo, e outros.

Nesse sentido, o encontro intersubjetivo e coletivo em sala de aula tornou-se propício para se discutir sobre os passados-presentes, ou seja, aqueles que se presentificam através de muitos demarcadores da diferença entre os sujeitos escolares e em nossa sociedade. Sendo assim, houve a preocupação em aguçar as subjetividades daqueles/as alunos/as, os/as fazendo sentir sujeitos da história, dos seus passados invizibilizados pela perspectiva colonial e eurocêntrica de história prescrita nos currículos oficiais. ${ }^{12}$ Nessa perspectiva, o interesse em desenvolver sobre os passadosvivos - como método de ensino construído pelas práticas sensíveis dos/as acadêmicos e regentes escolares - fez com que o debate sobre os usos do passado, juntamente com a historicidade de práticas de violência, extermínio e colonização dos corpos, levasse ao exercício educacional de uma história pública (ALMEIDA \& ROVAI, 2012; ALMEIDA, MAUAD, SANTHIAGO, 2016; ALMEIDA \& MENESES, 2018; SANTHIAGO, 2018; MAUAD, SANTHIAGO \& BORGES, 2018) ensinada associada

à proposta decolonial da educação histórica (GRINBERG, 2019). Para melhor elucidação desses conceitos, apresentamos, a seguir, as intervenções desenvolvidas em ambiente escolar, a saber, três comunidades escolares de Alfenas, como expõe o quadro abaixo:

\section{Projetos do Pibid do curso de História da Unifal sobre a temática afro- indígena (2014-2017)}

\begin{tabular}{|c|c|c|c|}
\hline & Projeto/Bolsistas: & Período: & Escola/turmas: \\
\hline \multicolumn{4}{|c|}{ Grupo 1: História da África } \\
\hline 1 & $\begin{array}{l}\text { As conexões entre Brasil e África. } \\
\text { Bolsistas: } \\
\text { Bianca*• } \\
\text { Gilsimara Bueno }\end{array}$ & $2^{\circ} \mathrm{sem} / 2014$ & $\begin{array}{l}\text { Estadual Dr. Napoleão Salles } \\
7 \text { e } 8^{\circ} \text { ano do Ensino } \\
\text { Fundamental }\end{array}$ \\
\hline 2 & $\begin{array}{l}\text { O ensino de História da África e } \\
\text { cartografia. }\end{array}$ & $2^{\circ} \mathrm{sem} / 2014$ & $\begin{array}{l}\text { Estadual Dr. Napoleão Salles } \\
8^{\circ} \text { ano do Ensino Fundamental }\end{array}$ \\
\hline
\end{tabular}

\footnotetext{
12 Sobre a formação dos currículos, cf.: GOODSON, 1995; SACRISTÁN, 1995.

- Os nomes grafados com asterisco referem-se a pessoas que não cederam entrevista, por isso usamos um nome fictício. Com exceção de Dandara (nome fictício) de uma das pibidianas que nos concedeu entrevista, todos (as) colaboradores (as) optaram por apresentar seus nomes de registro e autorização desses na divulgação das entrevistas. Todos (as) assinaram um termo de consentimento, autorizando o seu científico e divulgação de seus nomes pela pesquisadora.
} 


\begin{tabular}{|c|c|c|c|}
\hline & $\begin{array}{l}\text { Bolsistas: } \\
\text { Muriel Morgante } \\
\text { Vanessa Batista }\end{array}$ & & \\
\hline 3 & $\begin{array}{l}\text { Aprender África brincando } \\
\text { Bolsistas: } \\
\text { Muriel Morgante } \\
\text { Vanessa Batista } \\
\end{array}$ & $2^{\circ} \mathrm{sem} / 2014$ & $\begin{array}{l}\text { Estadual Dr. Napoleão Salles } \\
7^{\circ} \text { ano }\end{array}$ \\
\hline 4 & $\begin{array}{l}\text { Eu e o outro: O Perigo de uma } \\
\text { história Única } \\
\text { Bolsistas: } \\
\text { João Pedro Ribeiro de Oliveira; } \\
\text { Rafael Cappello e Renato* }\end{array}$ & $1^{\circ} \operatorname{sem} / 2017$ & $\begin{array}{l}\text { Estadual Dr. Napoleão Salles } \\
3^{\circ} \text { ano do Ensino Médio }\end{array}$ \\
\hline \multicolumn{4}{|c|}{ Grupo 2: História dos povos indígenas: } \\
\hline 5 & $\begin{array}{l}\text { Populações indígenas: diversidade } \\
\text { numa perspectiva histórica } \\
\text { Bolsistas: Gilsimara Bueno, } \\
\text { Fernando* }\end{array}$ & $1^{\circ} \mathrm{sem} / 2015$ & $\begin{array}{l}\text { Estadual Dr. Napoleão Salles } \\
7^{\circ} \text { ano }\end{array}$ \\
\hline 6 & $\begin{array}{l}\text { Diversidade e identidade indígena } \\
\text { brasileira: uma abordagem entre o } \\
\text { passado e o presente. } \\
\text { Bolsistas: Amanda Silva } \\
\text { Bianca* } \\
\text { Dandara* } \\
\text { Tatiana* } \\
\text { Victória Santos } \\
\text { Vanessa Batista }\end{array}$ & $1^{\circ} \mathrm{sem} / 2015$ & $\begin{array}{l}\text { Estadual Prefeito Ismael Brasil } \\
9 \text { ano do Ensino Fundamental } \\
1^{\circ} \text { e } 2^{\circ} \text { ano do Ensino Médio }\end{array}$ \\
\hline 7 & $\begin{array}{l}\text { Diálogos entre História e Literatura } \\
\text { na peça teatral "O Auto de São } \\
\text { Lourenço" de Pe. José de Anchieta. } \\
\text { Bolsistas: } \\
\text { Amanda Silva e Luis Guilherme de } \\
\text { Andrade. }\end{array}$ & $1^{\circ} \mathrm{sem} / 2017$ & $\begin{array}{l}\text { Estadual Dr. Emílio da Silveira } \\
2^{\circ} \text { ano do Ensino Médio }\end{array}$ \\
\hline 8 & $\begin{array}{l}\text { A questão do indígena na Ditadura } \\
\text { civil-militar brasileira } \\
\text { Bolsistas: Amanda Elias da Silva, } \\
\text { Luis Gustavo Firmino dos Santos e } \\
\text { Maria * }\end{array}$ & $1^{\circ} \mathrm{sem} / 2017$ & $\begin{array}{l}\text { Estadual Dr. Napoleão Salles } \\
9^{\circ} \text { ano do Ensino Fundamental }\end{array}$ \\
\hline \multicolumn{4}{|c|}{ Grupo 3: História da Escravidão e do Pós-abolição: } \\
\hline 9 & $\begin{array}{l}\text { Pensando a escravidão no Brasil a } \\
\text { partir da literatura: o que podemos }\end{array}$ & $1^{\circ} \mathrm{sem} / 2017$ & $\begin{array}{l}\text { Estadual Prefeito Ismael Brasil } \\
\text { Corrêa }\end{array}$ \\
\hline
\end{tabular}




\begin{tabular}{|l|l|l|l|}
\hline & $\begin{array}{l}\text { aprender em “A Escrava Isaura”? } \\
\text { Bolsistas: } \\
\text { Caroline Aparecida; Igor Vinicius e } \\
\text { Otávio Massaro. }\end{array}$ & $8^{\circ}$ ano \\
\hline 10 & $\begin{array}{l}\text { Crise na escravidão, processos pós- } \\
\text { abolicionistas e os reflexos na } \\
\text { sociedade atual. }\end{array}$ & $\begin{array}{l}1^{\circ} \text { sem/2017 } \\
\text { Bolsistas: Ana Carolina Dutra; } \\
\begin{array}{l}\text { Assucena Vanessa Lopes; } \\
\text { Mariele* }\end{array}\end{array}$ & $\begin{array}{l}\text { Estadual Prefeito Ismael Brasil } \\
\text { Corrêa } \\
8^{\circ} \text { ano }\end{array}$ \\
\hline
\end{tabular}

Dos dez projetos selecionados, os quatro primeiros - As conexões entre Brasil e África; O ensino de História da África e a cartografia; Aprender África brincando; e Os Perigos de uma História Única - foram desenvolvidos entre 2014 a 2017. De modo geral, as equipes pibidianas constataram, em suas avaliações de diagnóstico, a reificação do continente africano, ou seja, a ideia do continente como "país", além de outros preconceitos do senso comum, como o exotismo das culturas africanas, a pobreza endêmica de suas populações, como um dado a-histórico, a naturalização do negro como escravo e uma série de outros paradigmas que reforçam cotidianamente as narrativas do colonizador. Narrativas estas que desumanizam, invisibilizam e reificam os sujeitos colonizados, destituindo-lhes o papel de sujeitos históricos e agentes com capacidade de historicizar suas próprias memórias e experiências de mundo. Outro dado notável consistiu na ausência do tema tanto nos livros didáticos adotados, como nos currículos em ação praticados nas escolas. A África era exotizada, tida como espaço da barbárie, do local das constantes guerras da "não-civilização". Este olhar viciado sobre o continente reportava-se também às visões midiáticas e outros discursos não escolares que reverberam, de forma contundente, a narrativa impregnada da voz do colonizador, tão presente no habitus ${ }^{13} \mathrm{de}$ nossas leituras enviesadas, colonizadas pela visão eurocêntrica, acostumada a naturalizar os processos de violência e exaltar os lugares hegemônicos de poder e de saber. Os/as acadêmicos/as em formação se depararam com os primeiros desafios da docência: problematizar preconceitos e estereótipos, construir conhecimentos significativos, dialogar com as acepções prévias dos sujeitos escolares,

\footnotetext{
${ }^{13}$ Segundo Bourdieu (2007, p. 107), o conceito de habitus consiste na interiorização individual das proibições - estas impostas inicialmente por coerções sociais — transformadas em economia psíquica capazes de fortalecer os mecanismos de autocontrole exercidos sobre as pulsões emocionais para o exercício das ações em sociedade.
} 
desenvolver pedagogias alternativas distanciadas das concepções eurocentradas de história.

Desafios semelhantes tiveram os grupos que trabalharam a questão indígena, quando identificaram o mesmo tratamento de folclorização ao tratarem dos processos de identificação das comunidades e terras demarcadas no estado de Minas Gerais. O maior obstáculo consistiu em desmobilizar a imagem congelante do indígena, preso às representações literárias construídas por intelectuais dedicados a "desvendar" a identidade da nação brasileira. Dois projetos destacaram-se nessa temática. O primeiro "Diversidade e identidade indigena brasileira: uma abordagem entre o presente e o passado", desenvolvido em turmas de $1^{\circ}$ e $2^{\circ}$ ano do Ensino Médio, buscou trabalhar com o a sentidos de diacronia, "em uma perspectiva de passado/presente, com o foco nas etnias localizadas atualmente na região de Minas Gerais" (Proposta da Sequência Didática, 2015). O grupo procurou demonstrar que a "visão estereotipada do índio com cocar de penas, arco e flecha e isolado na floresta não apresenta o que é realmente ser índio" (Proposta da Sequência Didática, 2015). Além disso, a equipe pibidiana desenvolveu um estudo crítico acerca das disputas e demarcações de terras, o papel da mídia na desqualificação do movimento indígena e visão do colonizador fortemente arraigada no imaginário social hegemônico de diversos segmentos de nossa sociedade. $\mathrm{O}$ segundo projeto, intitulado "Populações indígenas: diversidade numa perspectiva histórica" diagnosticou as representações que compõem o imaginário dos alunos: os estigmas do "atraso" da "indolência", do congelamento de suas culturas no tempo, do mito da extinção e da romantização por meio da representação conservadora do "bom selvagem". Já o terceiro, "A questão do indígena na Ditadura civil-militar brasileira" visou investigar o uso da violência institucionalizada pelo Estado contra as sociedades indígenas durante o período da Ditadura Civil-Militar no Brasil. Em outra proposta, os discursos do colonizador foram problematizados em "Diálogos entre História e Literatura na peça teatral O Auto de São Lourenço de Pe. José de Anchieta”. As representações jesuíticas e o confronto com as cosmologias indígenas, através da deformação dos sujeitos colonizados, serviram como pontos de partida para analisar os processos de violência da colonização e suas (des) continuidades na contemporaneidade.

No último agrupamento de sequências didáticas, selecionamos os trabalhos centrados na questão da Diáspora Atlântica, as imagens da escravidão e as 
permanências e rupturas de uma sociedade profundamente enraizada nos parâmetros escravistas. O primeiro - "Pensando a escravidão no Brasil a partir da literatura: o que podemos aprender em A Escrava Isaura?" recorre à História Pública, ou seja, às representações das imagens da escravidão em frentes diversificadas, como a Literatura, novelas, cinema, etc.. Os/as pibidianos/as questionaram sobre a branquitude da escrava Isaura, as representações estereotipadas dos sujeitos escravizados e os valores aristocratizantes presentes nesta obra. Já na sequência intitulada por "Crise na escravidão, processos pós-abolicionistas e os reflexos na sociedade atual", os/as professores/as em formação desenvolveram um estudo de diacronia sobre as imagens do cativeiro no Brasil, a naturalização da visão do negro como escravo, o extermínio da juventude negra nos tempos atuais e a re-significação das práticas racistas enquanto elemento fundante da perpetuação do racismo estrutural. ${ }^{14}$

Diante do exposto, cada projeto, a seu modo, conseguiu desestabilizar os paradigmas presentes na narrativa hegemônica dos bancos escolares, calcada no silenciamento das experiências dos segmentos subalternizados pelo processo de violência colonial. Nesse sentido, houve descentramento da ótica colonizadora, ao subverterem a noção reificada do continente africano tomado, pela visão viciada, como antítese de civilização, do progresso e da razão. Isto posto, os grupos envolvidos nas sequencias didáticas não compactuaram com a folclorização dos grupos negros e indígenas, ao se recusarem tratar o conteúdo como apêndice do currículo eurocêntrico. Além disso, os/as acadêmicos/as trouxeram questionamentos quanto à redução da emergência das temáticas afro-indígenas exclusivamente em datas comemorativas. Sendo assim, as fissuras epistêmicas delinearam questionamentos contundentes sobre os desafios enfrentados pelo/a educador/a para inserir a temática étnico-racial na história ensinada e aprendida em sala de aula, considerando, os múltiplos vetores referenciais fora da escola que repercutem e coadunam com as imagens do racismo camuflado.

Embora, os projetos e relatórios não mencionassem diretamente os termos "decolonialidade", “justiça epistêmica" ou "descentramento do conhecimento", percebemos a preocupação constante em romper com a narrativa factual, eurocêntrica, com intuito de construir praticas emancipatórias de ensino, em que o aluno participa de modo ativo neste processo. Para Nilma Gomes (2005, p. 147), desenvolver uma

\footnotetext{
${ }^{14}$ Segundo Almeida (2018), o Racismo "é uma forma sistemática de discriminação que tem a raça como fundamento,e que se manifesta por meio de práticas conscientes ou inconscientes que culminam em desvantagens ou privilégios, a depender ao grupo racial qual pertençam".
} 
educação emancipacionista significa não só a ruptura com a história linear, etnocêntrica e factual. Descolonizar os modos de ensino-aprendizagem diz muito sobre a mudança de postura das atitudes e valores que são capazes de decodificar e superar as práticas segregacionistas, tão arraigadas no imaginário social do senso comum que ainda opera pela lógica do mito da democracia racial. Enfrentar o racismo epistêmico reporta-se à compreensão de que todas as epistemologias são políticas e que o saber é uma operação de poder. Dito de outro modo, os processos de subjetivação desses sujeitos constituíram-se em elementos sine qua non para compreendermos o lugar de enunciação, as sensibilidades e as posições políticas desses educadores enquanto seres cognoscentes que produzem conhecimento escolar e geram sentidos coletivos de aprendizagem capazes de gerar fissuras nas narrativas hegemônicas reproduzidas pelo currículo eurocentrado. Consideramos que a base oferecida pela política de formação inicial e continuada do Pibid, ao colocar em conexão intensiva a comunidade escolar e a universidade, viabilizou os instrumentos necessários para a produção do conhecimento compartilhado e colaborativo, inerente da história pública, em interface aos sentidos emancipatórios (pedagogia decolonial).

\section{3. "A melhor história pública que a gente tem é a sala de aula": a escolha docente e as narrativas de si}

"A melhor história pública que a gente tem é a sala de aula", disse Otávio Massaro - 21 anos, natural de Alfenas e professor de história na cidade de Serrania (MG) - ao responder uma pergunta sobre a emergência do revisionismo conservador e do negacionismo anticientífico nos discursos políticos propagados pelas plataformas midiáticas tradicionais e digitais em tempos em que a cultura do autoritarismo se coloca em destaque na ordem do discurso e das práticas de poder institucional (Gallego, 2018). O ex-pibidiano ainda mencionou:

Como eu disse, O PIBID foi uma coisa que me definiu como professor da Educação Básica, foi a peça fundamental que me fez continuar no curso. Me fez avaliar completamente a ideia de docência, do que seria ser professor. Que depois eu só fui ter contato no estágio né? E não é a mesma coisa que o pibid, infelizmente. (...) A gente aprende a sambar um pouquinho ali, entende? A gente tá fazendo, tá lidando ali, né? Sempre de trio, porque era muita gente, não tinha escola para todo mundo. Mas a gente tava ali, a gente fazia toda semana, a gente reunia e falava: "Como vai ser vai ser a nossa aula dessa semana? Quem vai fazer o quê? Então é como que a gente vai assumir a turma?" Aí você tava se preparando: "se acontecer algumas coisas erradas, se alguma coisa acontecer?" Porque se não acontecer a gente vai fazer de outro 
jeito. Nesse aspecto, a intervenção do professor supervisor é muito importante, né? Para a gente ter uma primeira autonomia na sala de aula, a supervisora deixava a gente bem vontade. Não interferia em nada, no conteúdo que a gente levava, ela dava "muito bom, tá ok"! E nesse aspecto, era muito bom, é isso mesmo a gente vai fazer! Vamos montar a aula desse jeito! "Vai levar essa imagem? Vai levar esse vídeo? Vai levar não sei o quê? E aí tudo isso é muito interessante as reações. Mas que eu preciso dizer mais? É que nesse momento eu tive o primeiro contato com a docência.... Foi o seguinte, eu tive certeza que eu tive umas aulas muito boas, muito legais. Mas eu tive outras que eu saí frustrado, que eu saí triste, que não obtive o resultado. E querendo ou não, a gente sendo professor a gente precisa aprender a lidar com isso. ${ }^{15}$

Pelo relato de Otávio foi possível perceber a ruptura com a percepção de uma escola romantizada, em que os alunos e alunas estariam sempre "prontos" para "receber" o conteúdo dado. Este processo de auto-reflexão e a percepção das dificuldades estruturais de uma escola real, e não idealizada, prepararam os (as) bolsistas para na construção de suas táticas e estratégias, através das intervenções planejadas de forma colaborativa entre a universidade/escola; escola/universidade. A partir deste relato e de muitos outros processos de escuta, sentimo-nos mobilizados a compreender como o Programa Institucional de Bolsa de Iniciação à Docência viabilizou possibilidades de construção dos sujeitos docentes e escolares, naquilo em que Nóvoa (2001) chama de "espaço concreto dos espaços formativos", isto é, no "chão da escola". Com isso, entendemos os saberes docentes não como algo externo à experiência de ensinar, mas como saberes múltiplos vinculados aos modos de ser no mundo desses sujeitos, produtores do conhecimento escolar e agentes históricos que atuam em seus contextos de experiências e constroem seus horizontes de expectativas (ADRADE, ALMEIDA, 2018, p. 132).

Nesse sentido, a integração - entre universidade, políticas públicas e escolas definiu espaços profícuos para a ação de sujeitos licenciandos e escolares que puderam produzir e compartilhar saberes emancipatórios a partir da própria experiência escolar, e não fora dela. Deste modo, as falas desses sujeitos não se colocaram sobre a escola, mas na experiência escolar, a partir de um olhar denso da cultura escolar. Este foi o "ponta pé inicial" para seguirmos os "fios e os rastros" de como os/as ex-pibidianos/as fizeram

15 Entrevista concedida por Otávio Maturano Massaro, Idade: 21 anos, natural de Alfenas-MG. Data da entrevista: 17 de abril de 2020. Profissão: professor de história. Período da graduação: 2017-2020. Período do Pibid: 2017-2018. Escola de atuação (Pibid): Estadual Napoleão Salles. 
uso, de modo crítico e responsável, dos debates públicos da história em espaços extraescolares e extra-institucionais, principalmente aqueles emergentes no campo midiático, levando em conta a premissa de Rüssel (2001) que outros espaços também ensinam algo sobre o passado e fazem com que os sujeitos construam sentidos para suas experiências no tempo.

Ao tratarmos sobre os projetos, referentes às temáticas afro-indígenas, preocupamo-nos delinear a construção das subjetividades/identidades neste processo de formação inicial do/as professores/as e suas narrativas contra-hegemônicas na efetivação do conhecimento da história ensinada. Em nossas sessões de entrevistas, perguntamos sobre questões, como: - "O que o Programa Institucional de Bolsa de Iniciação à Docência significou para suas vidas profissionais e pessoais?"; "Como fazer a sala de aula um espaço para se debater temas sensíveis e significativos às experiências dos sujeitos escolares?" Os diálogos foram densos e múltiplos, grande parte dos entrevistados descobriu suas identidades subjetivas como professor ou professora durante a participação ao programa de iniciação à docência.

Para respondermos a essas questões, optamos pelo exercício da escuta sensível acerca das trajetórias de vida desses/as educadores/as, ex-integrantes do programa de iniciação à docência. A sensibilidade da escuta consiste em uma ponte para alcançarmos os processos de subjetivação na elaboração dos saberes docentes. Partimos do pressuposto de que a memória oral é uma fonte viva e seus sujeitos produtores são coautores do processo de elaboração da entrevista. $O$ relato narrado pode ser compreendido como recriação afetiva daquele ou daquela que rememora acontecimentos a partir de intencionalidades e dinâmicas outras do tempo presente. Segundo Rovai e Boni (2010), os sujeitos entrevistados não são objetos da pesquisa, mas nossos interlocutores e co-laboradores e co-autores no processo da construção das narrativas de si. Segundo Rovai (2015), a "narrativa é fruto da interação e do encontro entre discursos, da intervenção do entrevistador, de um diálogo permeado por conflitos e diferentes expectativas, posições sociais, gêneros e conhecimento". Por isso a necessidade de compreender o encontro intersubjetivo oportunizado pela história oral como um processo dialógico em que o exercício da escuta por parte do investigador se torna fundamental para dimensionar a complexidade das experiências subjetivas narradas, estas, muitas vezes, carregadas de emoção, tabus ou traumas pessoais e/ou coletivos. 
Ao desenvolver sua narrativa, Vitória Larissa Ribeiro - 26 anos, natural de Manaus, participante do Pibid entre 2014-2015 - falou sobre a importância de se trabalhar a história viva em sala de aula, de humanizar o espaço escolar, de modo com que os (as) alunos (as) se vejam afetados com o conhecimento produzido através do processo de partilha e de troca nas relações interacionais em sala de aula. A mestranda da USP e também professora eventual na cidade de Taubaté (SP), fala da importância do Pibid para a definição do seu campo profissional como educadora e pesquisadora na área de história:

Sobre essa importância do PIBID na minha formação, acho que foi o que me fez gostar da minha formação de professora, é onde eu me entendi como professora, que eu não precisava ser uma professora que a gente tem quando fecha os olhos. Um outro tipo, outros horizontes. Eu acho que se não tivesse isso eu não teria tanto gosto, tanta paixão por aquela profissão. Eu gosto de tudo da história, eu acho que ser professora é também ser essa figura pública, ser essa figura de formação, de opinião, ser essa amiga também em alguns momentos, quando é preciso; ser também essa referência e a escola humaniza a gente de muitas formas e a gente não fica nessa torre de marfim que é a academia. Mas o PIBID foi de alguma forma também muito importante pra gente perceber o que ser pesquisador e ser educador não são coisas diferentes, na verdade, é uma integração e você é um bom professor quando você é um bom pesquisador também. Não existe um bom professor que pega da Wikipédia aquilo que ele quer ensinar e acabou. Mas aquele professor que pesquisa, que se envolve, que realmente vai atrás de bastante informação e essas informações não sejam simples e superficiais, (....). ${ }^{16}$

Para a licenciada, professor e pesquisador não podem ser entendidos em esferas opostas. Para ensinar é preciso pesquisar! Nesse sentido, a entrevistada considera que o conhecimento produzido em sala de aula não é mera reprodução, transposição simplificada ou narrativa externa às experiências dos sujeitos escolares. A história ensinada precisa ser viva. Ao tratar sobre os passados vivos em suas práticas em sala de aula, a colaboradora menciona:

E quando eu penso em fazer história, eu penso justamente nessa questão, nesse trabalho que ele e continuo, ele é diário, ele é um trabalho de enfrentamento, ele é arriscado, mas ele também é necessário, porque sem ele a gente não vive, não tem paz, enquanto não houver justiça histórica, a gente não vai ter paz nas nossas vidas.

16 Entrevista concedida por Vitória Larissa Ribeiro. Idade: 26 anos, natural de Manaus. Data da entrevista: 25/06/2020. Profissão: Professora eventual e mestranda em História Social na USP. Período do curso: 2012-2015; Período do Pibid: 2014-2015. Escola de atuação (Pibid): Estadual Prefeito Ismael Brasil Corrêa. 
Enquanto a gente não poder enterrar os mortos e quebrar esses monumentos de torturadores a gente não vai conseguir seguir e a gente precisa fazer isso em conjunto, no coletivo, porque se for hierárquico e unilateral se cria mais um problema. Então a história ela é sempre isso, esse jogo coletivo, trabalho de mosaico e de várias pessoas com vários pedaços e que alguns podem ser mais drásticos, outros menos drásticos, mas que no final eles vão formar um grande conjunto. E esse grande conjunto não é avanço nem de ré, mas ele é os dois. É um conjunto mesmo de formações, de vida, de experiências, de práticas, eu acho que isso de alguma forma se reflete no que a gente é também né? Eu acho que a história ela tem essa importância e essa questão fundamental. Ela não é uma coisa distante, tá tão próxima da gente, é tão parte da gente que a gente, às vezes, nem vê. Quando é muito próximo, às vezes, a gente nem vê. ${ }^{17}$

Em vista disso, a sala de aula foi entendida como espaço privilegiado para a prática de história pública, embora esta não constituísse em ato consciente da entrevistada durante sua atuação no Pibid, ou seja, não houve a preocupação em teorizar diretamente as práticas de história pública que já estavam acontecendo durante suas práticas de ensino-aprendizagem que dialogavam intensamente com os saberes históricos circulantes e presentes nas experiências sociais desses/as alunos/as. Isso acontecia quando narrativas construídas em sala de aula eram humanizadas e os agentes reconhecidos como sujeitos ativos dos processos históricos. A história viva, encarnada poderia ser doída, como mencionou Vitória, e ter feições reais, porque traziam as experiências correlacionadas ao modus vivendi dos sujeitos aprendentes. O que era distante se tornava próximo, vivo, palpável, era o uso dos "passados presentes" como método de ensino e de humanização do espaço de aprendizagem. Ao desenvolver o projeto sobre a história dos povos indígenas, Vitória, juntamente com Amanda, Dandara e Vanessa, relataram sobre a humanização enquanto abordagem de superação da da estereotipagem imposta aos povos indígenas, entendidos, frequentemente, como não sujeitos, destituídos de humanidade e agenciamento, por serem vistos como seres congelados no tempo e presos a um passado mítico. A narrativa de Vitória é exemplar, neste aspecto:

Eu acho que foi uma grande surpresa para os meninos terem visto esses grupos indígenas de Minas Gerais e terem pensado e entendido essa proximidade que isso tem, e ter entendido essa questão da

17 Entrevista concedida por Vitória Larissa Ribeiro. Idade: 26 anos, natural de Manaus. Data da entrevista: 25/06/2020. Profissão: Professora eventual e mestranda em História Social na USP. Período do curso: 2012-2015; Período do Pibid: 2014-2015. Escola de atuação (Pibid): Estadual Prefeito Ismael Brasil Corrêa. 
proteção cultural, pelo menos uma pequena parte dela. E que isso foi bem revelador pra eles, não verem esses indígenas como formas paradas no tempo, e verem as pessoas, e ao mesmo tempo que verem os indígenas, verem as pessoas, não verem outras culturas paradas no tempo. Eu acho que isso deu um movimento, um movimento na fala, um movimento na forma da gente lidar com a vida escolar, um movimento pra eles entenderem a história mesmo, foi bem dinâmico (...). ${ }^{18}$

Ao dialogarmos com Gilsimara Bueno Fonseca - 42 anos, natural de Serrania (MG), professora dos anos iniciais há mais de 20 anos - a colaboradora nos contou como foi trabalhar com o Projeto Conexões entre Brasil África nos sétimo e oitavo anos do Ensino Fundamental da Escola Estadual Dr. Napoleão Salles. Para a professora, o Pibid oportunizou re-elaborar e potencializar seus conhecimentos experenciais, profissionais e teóricos advindos de sua experiência da área de Pedagogia. Ela ainda nos relata que o programa de iniciação foi um ponto de inflexão em suas atuações como supervisora, regente e secretária da educação do município de Serrania:

Então, quando a gente foi com o projeto inovador do PIBID pra dentro da escola, isso gerou uma transformação, isso foi muito bacana e pra mim, enquanto professora, foi uma experiência inigualável, sabe? Foi muito bom! Eu pude me desenvolver muito, pude conhecer outros projetos e desenvolver vários projetos multiplicadores. ${ }^{19}$

A utilização de várias linguagens, como filmes, músicas, teatro, literatura, games e plataformas digitais, são pensados como recursos didáticos em potenciais para o desenvolvimento do letramento histórico entre adolescentes e crianças dos anos iniciais. Ao tratar sobre sua experiência no projeto Conexões entre Brasil África, a ex pibidiana, já educadora dos anos iniciais no período em que se graduou em história, relata acerca do despertar das identidades em sala, quando a temática das identidades negras tornouse o mote das intervenções planejadas desta sequência didática. Em uma das aulas, os alunos interpretaram um romance sobre Chico Rei, as pibidianas trabalharam de forma interativa com os vídeos-documentários sobre as congadas. Para a surpresa da equipe de intervenção didática, os alunos conheciam muito mais do que elas imaginavam sobre os

18 Entrevista concedida por Vitória Larissa Ribeiro. Idade: 26 anos, natural de Manaus. Data da entrevista: 25/06/2020. Profissão: Professora eventual e mestranda em História Social na USP. Período do curso: 2012-2015; Período do Pibid: 2014-2015. Escola de atuação (Pibid): Estadual Prefeito Ismael Brasil Corrêa

${ }^{19}$ Entrevista concedida por: Gilsimara Gomes Bueno Fonseca. Idade: 42 anos, Natural de Serrania-MG. Data da entrevista: 12 de março de 2020. Profissão: professora e supervisora pedagógica. Período da graduação: 2014-2017. Período do Pibid: 2014-2015. Escola de atuação (Pibid): Escola Estadual Napoleão Salles. 
ritos sagrados da congada, porque eram pertencentes de comunidades congadeiras e tinham raízes familiares de pertença ao rito festivo. Ao final da atividade, os (as) alunos (as) confeccionaram instrumentos musicais e trabalharam com as canções da congada:

\begin{abstract}
A gente precisava usar instrumentos que fosse do interesse dos alunos. Nós estamos passando por um momento que a internet né, a tecnologia chama muita atenção deles. Então, a questão dos vídeos foi até uma surpresa quando a gente usou o vídeo da Congada de Santa Efigênia, por quê? Porque muitos deles conheciam a Congada. Nós temos as nossas cidades aqui que culturalmente eles fazem né... eles têm a devoção à São Benedito, Santa Efigênia, Nossa Senhora do Rosário, e isso pra eles foi assim, algo que eles se identificaram. Então esse material, ele foi usado com intuito de despertar no aluno mesmo, o interesse pelo conteúdo. E pra nossa surpresa eles já conheciam muito mais o material que a gente estava levando, né. Por que? Porque muitos deles, os avós, os familiares fazem parte da Congada. ${ }^{20}$
\end{abstract}

Já com relação ao projeto sobre a escrava Isaura, ${ }^{21}$ Igor Vinicius - 25 anos, nascido na periferia de Belo Horizonte e professor da rede pública estadual de Minas Gerais - fala de como foi difícil tratar dos "passados vivos" quando o assunto é sobre a escravidão e a perpetuação do racismo estrutural na sociedade brasileira. O ex-pibidiano foi o agente responsável da equipe, formada também por Otávio e Caroline, para tratar da diacronia entre o período da escravidão e a exclusão étnicorracial na atualidade. Após fazer um trabalho de uso da literatura como fonte histórica, os bolsistas dialogaram constantemente com as cenas da novela Escrava Isaura ${ }^{22}$, problematizaram a estrutura diferenciada de linguagens, se apropriaram das representações do imaginário desses alunos e, por fim, fizeram o exercício de diacronia, discutindo temas como: o genocídio da juventude negra nas comunidades, a criminalização da pobreza, a violência policial nas periferias, o racismo estrutural no cotidiano, etc. Para a equipe pibidiana, os momentos de tensionamento aconteceram quando essas questões foram abordadas durante as aulas. A cena inicial do filme "Quanto vale ou é por quilo"23 foi utilizada como metáfora para problematizar as permanências das formas de violência,

20 Entrevista concedida por: Gilsimara Gomes Bueno Fonseca. Idade: 42 anos, Natural de SerraniaMG. Data da entrevista: 12 de março de 2020. Profissão: professora e supervisora pedagógica. Período da graduação: 2014-2017. Período do Pibid: 2014-2015. Escola de atuação (Pibid): Escola Estadual Napoleão Salles.

21 Projeto do Pibid: "Pensando a escravidão no Brasil a partir da literatura: o que podemos aprender em “A Escrava Isaura?”, realizado em 2017 na Escola Estadual Ismael Brasil Correa.

${ }^{22}$ Novela: Escrava Isaura (2004), Produção: Record TV. Direção: Herval Rossano. Roteirista: Anamaria Nunes, Altenir Silva. Novela inspirada no romance de Bernardo Guimarães (1875), reprisada pelo mesmo canal de TV em 2017.

${ }^{23}$ Filme: Quanto Vale ou é por quilo? Direção: Sérgio Bianchi, lançamento: 2005. 
exploração e desigualdades étnicorraciais na sociedade brasileira. Ao falar sobre as dificuldades de desnaturalizar preconceitos arraigados, Igor Vinícius, relatou suas experiências em sala de aula, o que testemunhou na periferia de Belo Horizonte. Sua narrativa construída em sala de aula, mesmo que de forma tensionada, conseguiu alcançar a sensibilidade dos alunos para temas centrados na violência racial e suas relações com o passado escravista.

\begin{abstract}
A gente não ta muito bem preparado pra fazer essas discussões em sala de aula, mas eu acho muito importante principalmente pela questão da violência assim, igual eu falei, "a minha violência", a minha experiência aqui no bairro, são experiências bem pesadas, de violência extrema. Direto meus amigos eram parados pela polícia, apanhava, eu era direto parado, a gente andava de moto aqui no bairro, sempre a gente era parado pela polícia. Já vi amigos meus morrendo, muitos amigos meus de infância já morreram, foram presos, quando eu entrei na faculdade eu senti uma necessidade muito grande de entender isso, tanto que eu entrei numa crise muito grande quando eu entrei, e eu acho que isso no ensino básico é muito importante, pra eles já começarem a construírem o próprio conhecimento deles sobre tudo! Mesmo que eles não estejam inseridos nesse cotidiano nessas violências, é essencial, assim, até mesmo pela questão da desigualdade social, pra gente não ter esses, pra não ter essas radicalidades depois né. Enfim, pra que eles minimamente possam repensar tudo isso, que eles tenham condições de fazer críticas, auto-críticas (...). ${ }^{24}$
\end{abstract}

\title{
4. Considerações Finais:
}

$\mathrm{O}$ estudo em andamento sobre as práticas do Pibid desenvolvidas em comunidades escolares de Alfenas, em parceria com a Unifal, nos faz refletir sobre a significância da história ensinada quando essas dizem respeito às experiências e vivências dos sujeitos envolvidos, sem exceção. A parceria pública proporcionada pelo programa de formação inicial e continuada de professores favoreceu o aspecto do trabalho colaborativo feito em cooperação, não só entre instâncias (universidade, Estado, escolas), mas, sobretudo por agentes diversos (coordenadores/as, supervisores/as, pibidianos/as e alunos/as). Deste modo, as ações produzidas e partilhadas coletivamente fortalecem a proposta da história pública em construir narrativas capazes de potencializar a formação de consciências históricas com o público e não só para o público. Outrossim, o trabalho com os passados sensíveis demonstrou a necessidade de se produzir narrativas contra-hegemônicas, em consonância com a

24 Entrevistado: Igor Vinícius Martins de Moraes, 25 anos. Natural de Belo Horizonte. Data da entrevista: 20/04/2020. Profissão: Professor de História. Período do curso: 2015-2020. Período do Pibid: 2017-2018.Escola de atuação (Pibid): Estadual Prefeito Ismael Brasil Corrêa. 
proposta da pedagogia decolonial, causando fissuras no currículo eurocentrado, externo às percepções e vivências dos sujeitos escolares. O diálogo com os debates públicos do passado em linguagens diversas (cinema, música, literatura, atc.) levou a discussão sobre os usos do passado e os significados construídos pelos sujeitos aprendentes acerca desses saberes circulantes. Por fim, concebemos que as práticas emancipatórias foram fundamentais para e produção dos processos de subjetivação por esses sujeitos ao narrarem suas memórias de si. Os modos de compreensão de seus espaços de experiências e horizontes de expectativas foram fundamentalmente atravessados por experiências multirreferenciadas, e pelos aprendizados forjados na ação coletiva pelo Pibid.

\section{Referências}

ALBERTI, Verena. Fontes Orais. Histórias dentro da História. In.: PINSKY, Carla (Org.) Fontes Históricas. $3^{\text {a }}$ Ed. São Paulo: Contexto, 2011, pp. 155-202.

ALMEIDA, Juniele Rabêlo de; MAUAD, Ana Maria; SANTHIAGO, Ricardo (Orgs.). História Pública no Brasil: sentidos e itinerários. São Paulo (SP): Letra e Voz, 2016.

ALMEIDA. Juniele Rabêlo; ROVAI, Marta Gouveia de Oliveira (Orgs.). Introdução à História Pública. São Paulo (SP): Letra e Voz, 2012.

ANDRADE, Everardo Paiva de; ALMEIDA, Juniele Rabêlo de. Trajetórias docentes e história pública: a construção de um acervo com narrativas de professores. In:

ALMEIDA, Juniele Rabêlo; MENESES, Sônia (Orgs.). História pública em debate: patrimônio, educação e mediações do passado. São Paulo (SP): Letra e Voz, 2018

ALMEIDA, Silvio Luiz. O que é racismo estrutural?. Belo Horizonte: Letramento, 2018.

BALLESTRIN, Luciana M. de A. Feminismos Subalternos. Estudos Feministas. V.25, n.3, 2007.

BAUMAN, Z. Identidade: Entrevista com Benedetto Vecchi. Rio de Janeiro: Jorge Zahar editora, 2005.

BOURDIEU, P. Razões práticas. Sobre a teoria da ação. $8^{\mathrm{a}}$ Ed. Campinas-SP: Papiros, 2007.

CÉSAIRE, Aimé. Discurso sobre o colonialismo. Lisboa: Sá da Costa, 1978.

DUSSEL, Enrique. Europa, modernidade e eurocentrismo. Em: LANDER, E (org.) A colonialidade do saber: eurocentrismo e ciências sociais. Perspectivas latinoamericanas. Buenos Aires. CLACSO, 2005, pp. 55-70

CERTEAU, Michel de. A invenção do cotidiano: V. 1. Artes de fazer. Petrópolis: Vozes, 2005.

ESCOBAR, Arturo. O lugar da natureza e a natureza do lugar: globalização ou pósdesenvolvimento. Em: LANDER, E (org.) A colonialidade do saber: eurocentrismo e 
ciências sociais. Perspectivas latino-americanas. Buenos Aires, CLACSO, 2005, pp. 63-79.

FANNON, Frantz. Os Condenados da Terra. Rio de Janeiro: Civilização Brasileira. 1968

FRAGO, Antonio Vinao. A história das disciplinas escolares. Rede Brasileira da História da Educação, Maringá, v. 8, n. 3 [18], 2008.

FREIRE, Paulo. Pedagogia da Autonomia. Saberes necessários à prática educativa. $25^{\text {a }}$ Ed. São Paulo: Paz e Terra, 1996.

GALLEGO, Esther. (Org.). O ódio como política. A reinvenção das direitas no Brasil. São Paulo: Boitempo, 2018.

GRINBERG, Keila. O mundo não é dos espertos: história pública, passados sensíveis, injustiças históricas. In.: História da Historiografia, v. 12, n. 31, 2019, p. 145-176.

GOMES, Nilma Lino. "Educação das Relações Raciais: Refletindo algumas estratégias de atuação. " In.: MUNANGA, K. (org.) Superando o racismo na escola. $2^{\mathrm{a}}$ Ed. Brasília: Ministério da Educação/SECAD, 2005, pp. 143-154.

GOMES, Nilma Lino. Relações étnico-raciais, educação e descolonização dos currículos. Currículo sem Fronteira, v. 12, n. 1, , abril-jan,2012, p 98-109.

LEE, P. Em direção a um conceito de literacia histórica. In. Educar, Curitiba, p. 131 150, 2006.

MIGNOLO, Walter D. Desobediência epistêmica: a opção descolonial e o significado de identidade em política. Cadernos de Letras da UFF - Dossiê: Literatura, língua e identidade, 34, 2008, pp. 287-324.

MONTEIRO, Ana Maria. Professores de História. Entre saberes e práticas. Rio de Janeiro: Mauad X, 2007.

MUNANGA, Kabengele. "Teoria Racial e Relações Raciais no Brasil." In.:Cadernos Penesb- Periódico do Programa de Educação sobre o Negro na Sociedade Brasileira FEUFF. Niterói/RJ: UFF, 2010, pp. 169-204.

NÓVOA, Antonio. Entrevista: Professor se forma na escola. In. GENTILE, Paola, Revista Nova Escola, Publicado em: 01/05/2001. Disponível em http://acervo.novaescola.org.br/formacao/formacao-continuada/professor-seformaescola-423256.shtml. Acesso em 23/06/2020.

PEREIRA, Nilton Mullet, PAIM, Elisson Antonio. "Para pensar o ensino de história e os passados sensíveis: contribuições do pensamento decolonial. In.: Revista Educação e Filosofia, v. 32, n 66, set/dez., 2018

QUIJANO, Anibal. Colonialidade do poder, eurocentrismo e América Latina. Em: LANDER, E. A colonialidade do saber: eurocentrismo e ciências sociais. Perspectivas latino-americanas. Buenos Aires, CLACSO, 2005, pp. 107-130.

ROVAI, Marta Gouveia de Oliveira. A ética da escuta: o desafio dos pesquisadores em História Oral. In.: Testimônios, Ano 4, nº 4, 2015, p.109-119.

ROVAI, Marta Gouveia de Oliveira. Ensino de História e a História Pública: os testemunhos da Comissão Nacional da Verdade em sala de aula. In.: Revista História Hoje, v. 8, n. 15, p. 89-110, 2019. 
ROVAI, Marta Gouveia de Oliveira. História Pública: a comunicação e a educação histórica. Revista Observatório, v. 3, p. 41-65, 2017.

ROVAI, Marta Gouveia de Oliveira. O direito à memória: a história oral de mulheres que lutaram contra a ditadura militar (1964 - 84). Revista Tempo e Argumento, Florianópolis, v. 5, n.10, jul./dez. 2013. p. $108-132$

ROVAI, Marta, BONI, Marcela. E. . Da fala à escrita: processos e procedimentos em busca da construção narrativa. História Agora, v. 9, p. 1-18, 2010.

RÜSEN, Jörn. Razão histórica - Teoria da história: fundamentos da ciência histórica. Trad. Estevão de Rezende Martins. Brasília: UnB, 2001.

SANTHIAGO, Ricardo. História pública e autorreflexividade: da prescrição ao processo. Revista Tempo $\quad$ E Argumento, $10 \quad$ (23), $286 \quad$ - 309, 2018. https://doi.org/10.5965/2175180310232018286

SANTHIAGO, Ricardo. MAGALHÃES, Valéria. "Rompendo o isolamento: reflexões sobre história oral e entrevistas à distância. Revista Anos 90, Porto Alegre, v. 27, 2020, p. 1-18.

SANTOS, Boaventura de Sousa. Para além do pensamento abissal: das linhas globais a uma ecologia dos saberes. In.: SANTOS, B. \& MENESES, M. P . (Orgs.). Epistemologias do Sul. São Paulo: Cortez, 2010, p. 31-83.

SACRISTÁN, J. G. "Currículo e diversidade cultural”. In: SILVA, T.T. e MOREIRA, A. F. (Orgs.). Territórios contestados. Petrópolis: Vozes, 1995.

SAID, Edward W. Orientalismo. São Paulo: Cia das Letras, 2003, pp. 27-163

SPIVAK, Gayatri Chakravorty. Pode o Subalterno falar? Belo Horizonte: Editora UFMG, 2010

WALSH, Catherine. Interculturalidade crítica e pedagogia decolonial: in-surgir, reexistir e re-viver. IN: CANDAU, Vera (org.). Educação intercultural na América Latina: entre concepções, tensões e propostas. Rio de Janeiro: 7 Letras, 2009. p. 12-43.

TARDIF, M. "Saberes profissionais dos professores e conhecimentos universitários: elementos para uma epistemologia da prática profissional dos professores e suas consequências em relação à formação para o magistério". In.:Revista Brasileira de Educação, São Paulo, ANPEd, n.13, jan.fev.mar.abril de 2000, p.5-24. 